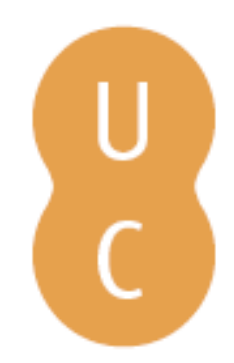

\title{
pommalina
}

\section{C.I. como agente (in) discreto na missão de Bolonha}

\author{
Autor(es): $\quad$ Pinto, Maria João; Fernandes, Sofia \\ Publicado por: Imprensa da Universidade de Coimbra \\ URL \\ persistente: URI:http://hdl.handle.net/10316.2/31915 \\ DOI: $\quad$ DOI:http://dx.doi.org/10.14195/978-989-26-0319-3_27
}

Accessed : $\quad$ 26-Apr-2023 06:35:32

A navegação consulta e descarregamento dos títulos inseridos nas Bibliotecas Digitais UC Digitalis, UC Pombalina e UC Impactum, pressupõem a aceitação plena e sem reservas dos Termos e Condições de Uso destas Bibliotecas Digitais, disponíveis em https://digitalis.uc.pt/pt-pt/termos.

Conforme exposto nos referidos Termos e Condições de Uso, o descarregamento de títulos de acesso restrito requer uma licença válida de autorização devendo o utilizador aceder ao(s) documento(s) a partir de um endereço de IP da instituição detentora da supramencionada licença.

Ao utilizador é apenas permitido o descarregamento para uso pessoal, pelo que o emprego do(s) título(s) descarregado(s) para outro fim, designadamente comercial, carece de autorização do respetivo autor ou editor da obra.

Na medida em que todas as obras da UC Digitalis se encontram protegidas pelo Código do Direito de Autor e Direitos Conexos e demais legislação aplicável, toda a cópia, parcial ou total, deste documento, nos casos em que é legalmente admitida, deverá conter ou fazer-se acompanhar por este aviso. 
Maria Manuel Borges

Elias Sanz Casado

Coordenação

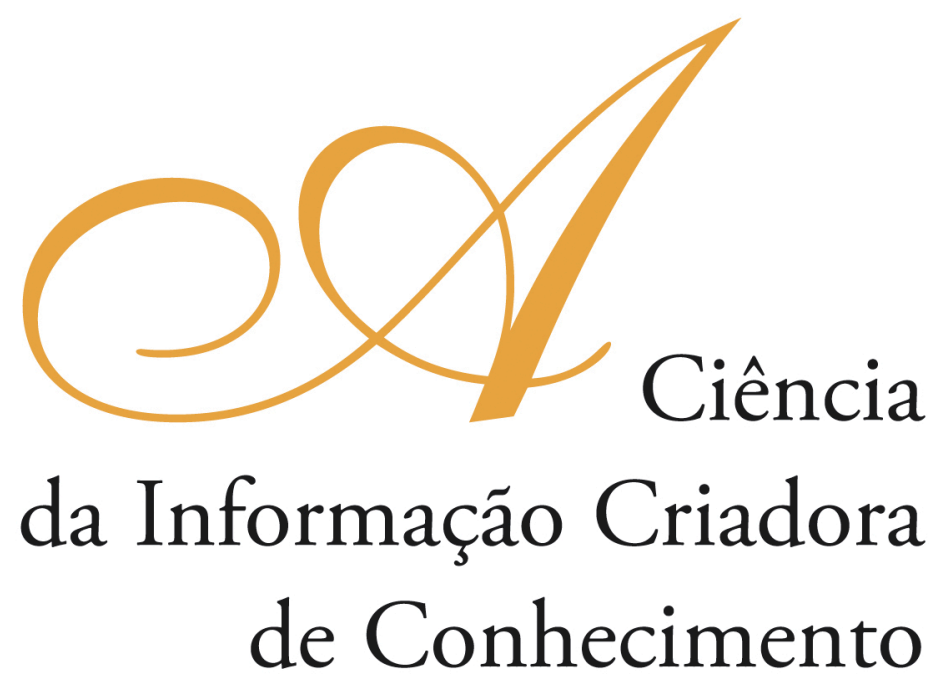

Vol. I

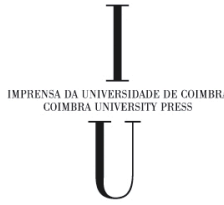

- COIMBRA 2009 


\title{
C.I. COMO AgENTE (IN) Discreto NA Missão de Bolonha
}

\author{
Maria João Pinto \\ Universidade Católica Portuguesa (Portugal)
}

Sofia Fernandes

\section{Resumo}

A presente comunicação pretende contribuir para o processo de dinamização do perfil profissional de Ciência da Informaçáo $(\mathrm{CI})$, nomeadamente no contexto das bibliotecas do Ensino Superior ibérico. O objectivo consiste em demonstrar como o profissional de CI tem um papel relevante e vital no que diz respeito aos desafios propostos pelo Tratado de Bolonha e, assim, procurar disseminar estratégias, esforços e medidas conjuntas por uma Universidade Europeia do Conhecimento.

Sendo o contexto o Ensino Superior (ES) com os novos valores e perspectivas pedagógicas decorrentes do Processo de Bolonha, faz sentido apresentar resumidamente os respectivos objectivos e pressupostos e as inovaçóes pedagógicas que se fizeram sentir.

Serão analisadas algumas implicaçóes no meio académico resultantes do processo em questão, nomeadamente nas bibliotecas do ensino superior.

No seguimento do impacto que o novo modelo tem neste âmbito, será demonstrada a importância de Ciência da Informaçáo na biblioteca do ES para ser capaz de responder aos novos desafios levantados e ter um contributo proactivo em prol de uma aprendizagem colectiva e competente.

Finalmente, é apresentada uma breve conclusão sobre a parceria do profissional de CI na responsabilidade social e pedagógica de futuro.

\begin{abstract}
This Communication intends to contribute to the process of boosting the profile of Information Science, particularly in the context of iberian Higher Education libraries. The aim is to demonstrate how the work of CI has a vital and important role with regard to the challenges offered by the Treaty of Bologna, and thus seek to spread strategies, measures and joint efforts by a European University of Knowledge.

Since the Higher Education with the new values and perspectives of teaching arising from the Bologna Process, it makes sense to briefly present their objectives, assumptions and pedagogical innovations to be felt.

Some implications are examined in academia from the case in question, particularly in the libraries of higher education.

Following the impact that the new model is, in this context, will be demonstrated the importance of Information Science at the library of Higher Education to be able to meet the new challenges raised and have a proactive contribution to a collective and competent learning.

Finally, expose a brief conclusion on the partnership of the professional in Information Science in social responsibility and education for the future.
\end{abstract}




\section{Introdução}

Em 1999, vinte e nove países assinaram o Tratado de Bolonha no sentido de reformar o ES e criar uma Europa de Conhecimento com o objectivo de funcionar, em pleno, em 2010. A reforma consiste numa linha orientadora comum para consolidar a educação superior europeia, possibilitar e fomentar a mobilidade, quer dos estudantes quer dos professores, e a competitividade internacional (Do, 2008).

Bolonha foi antecedido pela Declaração de Sorbonne em 1998 e complementado pelos trabalhos de Praga e Berlim em 2001 e 2003 respectivamente.

Os objectivos pressupóem a adopçáo de um sistema de base transparente e de fácil leitura, unificado por graus comparáveis e coerentes. Assim, trata-se de um sistema assente, principalmente, em dois ciclos vitais (estudos de grau e post grau), com um regime de créditos (ECTS - sistema europeu de transferência) e modelos de currículos válidos e transitáveis no circuito europeu (Silva et al., 2009).

Enquanto o sistema anterior de créditos limitava-se a quantificar as horas empregues pelos estudantes nas aulas, teóricas e práticas, o ECTS pretende alargar o período para a aprendizagem total, sendo contabilizado o tempo dispendido em seminários, oficinas, conferências e, ainda, na realização de trabalhos (Mas, 2006).

As directivas propostas pelo Tratado estimulam a cooperação europeia para assegurar a qualidade baseada em critérios e metodologias compatíveis. Não obstante, um dos princípios passa por respeitar e assegurar a riqueza individual e autonomia de cada país.

\section{Missão Bolonha}

As directivas de Bolonha incidem no desempenho e imagem da universidade, na mudança de paradigma de ensino e no papel dos professores e dos estudantes (Trujillo, 2004). A universidade enfrenta as consequências e normas da globalização. Actualmente, a universidade sente uma constante necessidade de mudança, adaptabilidade e de cooperação internacional para fazer face às novas exigências e padróes de qualidade.

Neste processo comum para as universidades europeias, é vital que se verifique um aumento de transparência na respectiva performance que permita a mobilidade e a comparabilidade. Para atingir o sucesso, as universidades têm de cooperar entre si e criar mecanismos de comunicação, colaboração e networking (Moscoso, 2003).

A Declaração de Bolonha aufere critérios de eficácia e eficiência para o meio universitário e declara uma cultura de qualidade. Evidencia uma ruptura nos paradigmas do quotidiano da prática pedagógica universitária, nova concepção de conhecimento que aspira uma Europa coesa e competitiva (Peyrolon, 2005).

O papel da universidade na Sociedade da Informação é constituir-se como articuladora do conhecimento provocando, segundo Rodrigues e Dumont (2004) citando Benhrens ${ }^{1}$, "um estado permanente do indivíduo, onde o trabalho colaborativo está sempre presente”.

\footnotetext{
${ }^{1}$ Benhrens, M. A. (1999). A Prática pedagógica e o desafio do paradigma emergente. R. Bras. Est. Pedag., 80(196), 383-403
} 
O novo paradigma resultou, naturalmente, nas mais diversas implicações com todos os elementos organizacionais de cada universidade que se traduziu num esforço de adaptação e reorganização no alinhamento colectivo de vários serviços, em especial, da biblioteca.

Apesar de a biblioteca náo ser referida explicitamente no Tratado de Bolonha, na prática, desempenha um papel decisivo para a concretizaçáo da sua missão e objectivos.

No entanto, para ter sucesso neste desafio, é vital a criação de um novo modelo de biblioteca e a existência de novos perfis profissionais com competências ao nível das novas tecnologias de informação e comunicação e de gestão de informação.

$\mathrm{O}$ novo modelo reveste-se da responsabilidade de ser capaz de responder às novas necessidades académicas. Ou seja, a biblioteca transforma-se num serviço estratégico que permite aos estudantes e docentes acompanhar com sucesso o processo de aprendizagem estabelecido pela Declaração. Este modelo dá a conhecer a função social do conhecimento e da aprendizagem.

O papel da biblioteca passa a ser de intercâmbio/interlocução e interpretação na transformação da informação em conhecimento (Gómez et al., 2003).

\section{Novo Paradigma de Aprendizagem}

Apesar de ter sofrido gradualmente significativas mudanças, o método de ensino assentava, ainda, numa transmissão de saberes cujo elemento principal era o próprio professor e o conhecimento transmitido. Segundo Rodrigues e Dumont (2004) citando Masetto²: "na grande maioria das situaçôes ainda encontramos o professor no papel [somente] de transmissor de informaçôes, e mesmo actuando só com aulas expositivas".

O novo modelo valoriza o processo de ensino-aprendizagem que foca o processo de aquisição de conhecimento, em detrimento do processo unilateral de ensino, e o agente activo do processo é o aluno quem irá assumir o controlo da própria aprendizagem através da investigação. A palavra-chave já não é educação, mas sim aprendizagem.

$\mathrm{O}$ estudo deixa de ser individual, dando lugar à aprendizagem colectiva. Sáo exigidas meta-competências e não apenas competências específicas.

O professor não é delegado para um segundo plano, mas adopta um perfil mais determinante, pois será o responsável por guiar e orientar o estudante neste processo de conhecimento e fomentar a criação de grupos de estudo/trabalho. Assim, o seu papel é de facilitador e motivador, em vez de instrutor.

De facto, assume a função de "agente articulador do novo paradigma de ensinar e aprender na universidade” sendo necessário um aprofundamento das competências ao nível do conhecimento de carácter inovador e crítico (Rodrigues \& Dumont, 2004, p. 9).

O modelo de aprendizagem assenta nas competências base da Literacia da Informação, como componente imprescindível no âmbito curricular, e defende que a

\footnotetext{
${ }^{2}$ Masetto, M. T. (2003). Competência Pedagógica do professor universitário. São Paulo: Summus
} 
aquisição/criação de conhecimento não é exclusivamente dentro da sala de aula nem apenas durante o período universitário. Defende o modelo de aprendizagem ao longo da vida, em detrimento da aprendizagem universitária (Peterson, 2006).

O estudante depara-se com novos desafios e exigências e assume um papel de coresponsável, na íntegra, ao longo do processo de aprendizagem. Enfrenta o compromisso de procurar a informação, localizá-la para analisar e relacionar com conhecimentos anteriores - Aprendizagem Significativa (Silva et al., 2009). O objectivo é que ele próprio encontre o respectivo significado, conclua as percepçóes adequadas, registe os casos estudados e trabalhe esses dados.

Segundo Rodrigues e Dumont, (2004) citando Benhrens ${ }^{3}$, a próxima geração de estudantes são pesquisadores autónomos de informação pois "a sociedade passa a exigir profissionais que tenham capacidade de tomar decisóes, que sejam autónomos, que produzam com iniciativa própria, que saibam trabalhar em grupo, que partilhem suas conquistas e que estejam em constante formação".

A concepção do ensino com a pesquisa significa a ruptura da reprodução de conhecimento. Surge a oportunidade para o reaparecimento da produçáo do conhecimento original de forma autónoma e com espírito crítico e inquisitivo.

Este modelo activo de aprendizagem impóe-se em detrimento da absorção passiva de conteúdos. A nível da criação do conhecimento, emerge a importância da pesquisa e investigação colaborativa e a respectiva internacionalização. Surge a consciência de promover a produção e a disseminação do conhecimento, principalmente, através de novas tecnologias de informação, recursos de aprendizagem e canais de comunicação como, por exemplo, o ensino à distância, o e-learning, etc (Geleijnse, 2005).

Novas formas de publicação e comunicação científica estão a ser fomentadas e impulsionam os avanços científicos e de inovação nas organizaçôes obtendo um carácter interdisciplinar.

No que diz respeito às novas tecnologias e respectivos recursos electrónicos, bases de dados de referência bibliográfica, a habilidade de utilização e proficiência é agora, mais do que nunca, uma competência imprescindível para a aprendizagem autónoma de pesquisa e investigação.

É vital uma metodologia adequada no sentido de orientação, prossecução da pesquisa e automatização do processo de referências bibliográficas.

\section{Centro de Recursos}

No contexto presente de mudança, a biblioteca do ensino superior enfrenta desafios e responde-os através do fornecimento, em contexto real e adequado, dos recursos de informação necessários em colaboração com o ensino. $\mathrm{Na}$ verdade, a separação existente entre a docência e a utilização das novas tecnologias tende, gradualmente, a desaparecer (Azevedo et al., 2006).

Neste sentido, a biblioteca deixa de ser intermediária e torna-se parceira do ensino pois tem de se adaptar ao novo modelo pedagógico.

\footnotetext{
${ }^{3}$ Benhrens, M. A. (1999). A Prática pedagógica e o desafio do paradigma emergente. R. Bras. Est. Pedag., 80(196), 383-403
} 
A disponibilização de recursos de informação assume um carácter indispensável para o desenvolvimento do processo de aprendizagem e conhecimento pela intensiva necessidade de utilização de informação.

Os novos métodos de ensino e aprendizagem exigem ao serviço um acesso à informação e a ferramentas tecnológicas cada vez mais rápido, móvel e seguro, uma maior utilização do espaço (físico e virtual) e uma procura de novos serviços.

Para o domínio das TIC's, é necessário o apoio da universidade para a adopção de uma infra-estrutura tecnológica que permita a colaboração entre ambas de projectos académicos (Peyrolon, 2005).

No que se refere aos recursos electrónicos, assistimos ao aumento da exigência quanto à actualização e disponibilização de recursos adequados. Neste âmbito, destacamos a importância da página web da biblioteca cujo objectivo é informar os utilizadores, criando espaços próprios para cada perfil/necessidades de forma a fornecer informação dirigida e à medida (Do, 2008).

São ainda imprescindíveis softwares especializados, assistência informática, serviços de produção audiovisual e multimédia para a criação de valor acrescentado.

Numa perspectiva cronológica, as colecçôes dão lugar às conexôes e, por outro lado, se a polémica da informação focava a sua escassez, agora a informaçáo é dispersa e em excesso (overload information). Neste sentido, um dos grandes objectivos para os profissionais de informação é a avaliação e selecção de informação para os seus utilizadores, assegurando a info-inclusão (Silva, 2008).

A biblioteca, como centro de recursos para a aprendizagem e para a investigação, constitui-se como a mediadora ideal no processo da aprendizagem na medida em que proporciona ferramentas de educação, salas de estudo, horários alargados, conexóes disponíveis, espaços físicos e virtuais, informação, formação e experiência. Oferece, ainda, infra-estruturas e apoio aos professores para uma melhor optimização das tecnologias disponíveis através de formação especializada e dirigida.

Uma actividade adicional é a gestão de conhecimento e a gestão integrada de informação no que diz respeito aos recursos e serviços de informação existentes nos sistemas de gestão. Esta integração envolve os objectos de aprendizagem nos sistemas de informação digitais e a gestão dos conteúdos de aprendizagem em directórios, bibliotecas digitais e, ainda, na colaboração nas plataformas de e-learning e tutoriais on-line (Peterson, 2006).

As universidades estão a disponibilizar, num modelo de livre acesso, a produção científica institucional através da criação de repositórios digitais.

Os repositórios institucionais respondem aos desafios actuais da produção e disseminação do conhecimento pois permitem a organização e optimização dos recursos electrónicos, facilidades na produção e no acesso da informação produzida e, ainda, o aumento da visibilidade, reputação e transparência das universidades.

Com a colaboração do departamento informático, a biblioteca tem sido a protagonista no processo na medida em que é responsável pela organização, aplicação de procedimentos, inserção de metadados, gestão e manutenção do repositório.

Simultaneamente, a biblioteca tem-se constituído como um agente de articulação e promoção ao divulgar e sensibilizar a comunidade científica face ao objectivo e vantagens do processo, para ambos os intervenientes e para a própria sociedade. 
A grande mudança para a biblioteca será tornar-se num centro de estudo, com salas de estudo diferenciadas e adequadas ao trabalho em grupo com todos os recursos necessários: computadores em número adequado ao número total de alunos, ligaçóes para portáteis, wireless, etc. (Geleijnse, 2005).

Outro factor importante, de natureza inerente, é que se trata de um serviço presente em todas as instituiçóes de ES.

Se é pretendido que o estudo seja realizado em grupo, os alunos necessitam de um local físico em que se possam encontrar e de ter acesso às ferramentas e recursos de informação necessários. Portanto, é de todo o interesse a criação de relaçóes colaborativas entre a biblioteca, os serviços informáticos, docentes, alunos e administração com base numa visão conjunta e partilhada da Universidade. Isto é, a convergência de recursos e serviços distintos mas com objectivos comuns: um ensino de qualidade através da oferta de serviços de excelência e de fácil acesso num espaço com serviços integrados numa infra-estrutura adequada.

No Reino Unido, muitas bibliotecas já adoptaram este modelo e em Espanha as mudanças estão a ocorrer visivelmente (Do, 2008).

Segundo Boy (2006), "o objectivo final é criar um espaço físico e virtual onde o estudante desenvolva a sua aprendizagem e o professor e investigador encontrem todo o apoio e infra-estruturas necessárias para a elaboração de conteúdos pedagógicos e realização das suas investigaçóes" (p. 3).

As bibliotecas de ensino superior tiram, desta forma, vantagem da mudança pois deparam-se com a oportunidade de transformarem-se em centros de recursos para a aprendizagem e para a investigação (Gómez et al., 2003).

Muitas missões de bibliotecas de ES prendem-se com a selecção, recuperação, organização e transmissão de informação ou conhecimento.

$\mathrm{Na}$ verdade, há uma certa confusão entre os conceitos de missão e actividade.

Os processos de pesquisa, tratamento e fornecimento de informação constituem as actividades do serviço.

Por missão, entende-se o objectivo dessas actividades.

Segundo Petersen, citando Dempsey ${ }^{4}$ : "We do not do these things by and for themselves. We do them in order to address an important and continuing need of the society we seek to serve, we do it to support learning".

No seguimento de uma nova realidade, objectivos institucionais e perfis profissionais (CI), a missão de uma biblioteca de ES deverá ser reinventada.

Segue-se um modelo, a ser estudado e adaptado de acordo com cada caso específico, da missão e visão de uma biblioteca na prossecução das linhas orientadoras de Bolonha:

Ser um colaborador activo e vital do meio académico ao disponibilizar recursos de informação necessários ao desenvolvimento do processo de aprendizagem e, ainda, de criação, utilização e disseminação do conhecimento.

Comprometermo-nos a desempenhar as nossas funções de transmissão e fomento das competências necessárias para transformar a informação e abrir as portas do Conhecimento.

\footnotetext{
${ }^{4}$ Dempsey, L. (2004). European Conference on Digital Libraries
} 


\section{Literacia da Informação}

Outro aspecto, tão importante quanto a disponibilização de recursos, é o conhecimento/domínio de utilização dos mesmos e a qualidade da recuperação de informação (UNICA, 2006).

Esta necessidade requer a existência de recursos humanos aptos e competentes no domínio das novas tecnologias de informação, quer para a utilização, quer para a formação de utilizadores.

Num momento em que nos deparamos com uma explosão informacional, emerge a ideia de Literacia de Informação e as directivas da Declaração de Bolonha revestemna de relevância superior e inevitável concretização, pois a emergência de um novo modelo na educação implica novas competências.

O Processo de Bolonha vem reafirmar a importância das competências ao nível das tecnologias de informação. Portanto, outro contributo essencial que a biblioteca deverá apostar será ao nível formativo. Este tipo de intervenção terá de ser concretizado por profissionais de informação e ajustado ao tipo de utilizador (docentes, alunos de licenciatura, de mestrado e de doutoramento) e às diversas modalidades actualmente disponíveis (presencial, e-learning, b-learning, tutoriais) com as actuais necessidades do utilizador no filtrar de informação pertinente.

Segundo Mas (2006), já em 1997 o Dearing Report da Biblioteca Nacional da Universidad Carlos III de Madrid, recomenda: "Todas las instituciones den prioridad al desarrollo de estrategias de enseñanza y aprendizaje enfocadas a la formación de los estudiantes" (p. 2).

Apesar de termos assistido a um aumento considerável de recursos de informação e de ser reconhecido aos estudantes um conhecimento e desempenho adequados na respectiva utilização, estes, ao entrarem no ensino superior, não possuem as competências elementares de pesquisa de informação (Silva, 2008). No entanto, trata-se de um dos preceitos mais valorizados na Sociedade de Informação.

O empenho, por parte dos profissionais de informação, no que diz respeito à pesquisa, recuperação, avaliação e utilização da informação pretendida, vai de encontro às competências estimuladas pela Declaração ao nível da aprendizagem ao longo da vida e está presente na formação de CI.

O conceito de Literacia de Informação, é o "conjunto de competências que permitem reconhecer a necessidade de informação e actuar de forma eficiente para suprir essa necessidade, obtendo informação, avaliando-a e revendo o processo de pesquisa" (Pacheco, 2009, p. 1) de forma útil e criativa na tomada de decisão e resolução de problemas.

As competências inerentes e pretendidas no bom domínio da information literacy são: identificar a natureza e dimensão da necessidade, ponderar, sob um olhar crítico, a informação obtida e respectivas fontes, associar a informação com conhecimentos apreendidos e percepcionar as questôes legais ou éticas implicadas na utilização da informação. Para uma correcta avaliação da informação, é indispensável seguir critérios de pertinência, relevância, lógica e objectividade (Silva, 2008).

O produto final é a criação de novas informaçôes, necessidades informacionais e significados, de forma autónoma, através de uma aprendizagem ao longo da vida essencial à tomada de decisão quer no âmbito profissional quer no campo pessoal/social. 
Programas de formação a utilizadores já faziam parte das práticas das bibliotecas de ensino superior na Alemanha, Reino Unido e países escandinavos. Ao sentirem o crescente volume de informação verificado, responderam com programas de Literacia de Informação (Pacheco, 2009). Entretanto, essa consciência ainda não está concretizada, na prática, nas instituiçóes de ensino superior europeias. Nomeadamente em Portugal, ainda abarca um carácter facultativo.

Antecipando Bolonha, a Escola Superior de Biotecnologia da Universidade Católica Portuguesa contou com alguma experiência na introdução de formação ao nível da Literacia de Informação, em contexto de sala de aula. De facto, a aproximação do bibliotecário à função pedagógica, em âmbito curricular, mostrou-se francamente positiva. A experiência foi muito bem recebida pela comunidade académica que demonstrou entender a importância do tema e a sua utilidade no percurso universitário.

As aulas de Literacia promoveram uma compreensão ao nível das necessidades informativas e incitaram comportamentos adequados e técnicas eficazes para a recuperação e organização de informação em contexto de estudo e da prossecução de trabalhos. $\mathrm{Na}$ verdade, os professores manifestaram o seu contentamento ao perceber a evolução e melhoria do desempenho dos estudantes.

Desta forma, testemunhamos a necessidade e comprovamos a eficácia e bons resultados da introdução da respectiva formação no plano curricular.

Em relação ao papel da biblioteca de ES no processo educativo/formativo, a questão já não é ser um complemento à sala de aula mas sim parte da sala de aula. Assistimos à transfiguração da antiga imagem do professor-bibliotecário na de bibliotecário-professor (Pacheco, 2009). O mesmo autor, citando Correia e Teixeira5, "Academic librarians must assume the responsability for creating opportunities for students to acquire this skill, during their library user education".

No entanto, será necessário disseminar esta problemática junto ao corpo docente para uma colaboração articulada e consciente entre eles e a biblioteca. De facto, alguns professores demonstram uma certa relutância em dispensar tempo e espaço lectivo para tais programas (Pacheco, 2009).

Como já foi anteriormente referido, a colaboração é a palavra-chave, a nível interno e externo, para um ensino de qualidade.

A contínua formação, actualização, aperfeiçoamento e reciclagem de conhecimentos é essencial para todas as áreas, no caso da biblioteca será obrigatório pois dela dependerá a formação de outros elementos.

\section{O agente Ciência da Informação}

A Sociedade da Informação representou um fenómeno de profunda mudança de paradigma sócio-cultural no que diz respeito aos profissionais de informação, à própria ideia de informação e ao contexto das bibliotecas, nomeadamente no ES.

\footnotetext{
${ }^{5}$ Correia, A. M. R. \& Teixeira, J. C. (2003). Information literacy: an integrated concept for a safer Internet. Online Information Review, 27 (5), 311-320.
} 
A irrefutável produção, utilização e valorização massiva e imprescindível da informação impôs um redireccionamento e reestruturação da formação académica do profissional.

Como resposta à imposição destes novos desafios e matrizes epistémicas, foi criada uma formação superior denominada de Ciência de Informação. A sua base epistemológica assenta na necessidade de um perfil de natureza interdisciplinar com capacidade de compreender o contexto complexo, heterogéneo e global actual.

As novas exigências passam por serviços de excepcional qualidade a partir das mais recentes ferramentas tecnológicas ao dispor. CI, a partir de uma componente tecnológica especializada nas TIC's, constitui-se como a formação adequada às novas exigências na biblioteca do ES.

A partir de uma perspectiva holística, CI tem como pilar metodológico o Método Quadripolar e abraça três áreas distintas mas correlacionadas: Gestão de Informação, Organização e Representação de Informação e Comportamento Informacional. Trata-se de uma formação poliédrica por resultar de um bloco unitário com diversas articulaçôes complementares (Silva \& Ribeiro, 2008). As valências multidisciplinares, trandisciplinares ou interdisciplinares proporcionadas aos profissionais da área são completamente ajustadas à escala da Sociedade de Informação e da própria revolução pedagógica instituída por Bolonha.

No que diz respeito à Literacia de Informação, Silva (2008) alude "a [sua] inteligibilidade (...) se instaura, em pleno, na área do comportamento informacional, sendo, como este, um tópico exógeno a Ciência de Informação" (p. 19). Logo, é evidente a compatibilidade do perfil tratado na metodologia de investigação e pesquisa de informação como formação requerida, para o corpo docente e de estudantes, sob os imperativos da Declaração.

A reestruturação e proliferação de áreas de saber (cursos superiores) foi crescendo ao longo dos anos e este fenómeno mantém-se. Portanto, a diversidade das áreas às quais as bibliotecas de ES necessitam de responder constituem um desafio para o profissional. Este necessita de uma formação de base flexível e abrangente para uma natural adaptação e respostas mais compreensivas e eficazes.

$\mathrm{CI}$, como fruto de um plano de estudos equilibrado, reúne as tradicionais disciplinas de Arquivística, Biblioteconomia e Documentação, complementadas por várias áreas científicas, e aliadas a uma forte e especializada componente de Sistemas Tecnológicos de Informação. Assegura as competências de pesquisa, selecção, identificação, organização, avaliação e validação da informação e respectivas fontes para uma utilização, tratamento e gestão adequadas. Desta forma, assume-se como melhor aposta das bibliotecas do ES para estar à altura dos desafios pedagógicos estipulados pela Declaração de Bolonha e pelos actuais planos curriculares.

Segundo Rocha e Araújo (2007), as Competências Informacionais constituem um "procedimento contínuo de interacção e internacionalização à compreensão da informação, das capacidades necessárias para a geração de novos conhecimentos e sua aplicabilidade ao longo da vida, saber agir e tomar decisóes e desenvolver habilidades" (p. 5).

Um inquérito, efectuado pelos mesmos autores, aos utilizadores de uma biblioteca de ES no Brasil, divulgou que as principais competências dos especialistas de informação, por ordem de relevância são: 
1. Trabalho em equipa

2. Habilidade frente às novas tecnologias

3. Perfil de gestor

3.1. Planeamento

3.2. Administração de recursos humanos

3.3. Liderança

4. Postura pró activa

5. Sentido ético

Como podemos observar, as competências tradicionais perdem alguma relevância e dão lugar às chamadas competências transversais e às competências tecnológicas.

Nesta questão, é valorizada a formação de CI nos temas da gestão, administração, Sociologia das Organizaçóes e Direito Informacional.

No domínio científico, as competências de CI estendem-se ao apoio, promoção e divulgação da produção de conhecimento científico através do levantamento, recolha, estudo, análise da produção científica para relatórios de avaliação, avaliação bibliométrica, apoio à manutenção de CV's e criação e gestão de repositórios institucionais.

CI pretende constituir-se como um agente facilitador, mediador e fomentador da aprendizagem e disponibilizar a satisfação das necessidades decorrentes do processo. Toda a mudança de paradigma pedagógico e organizativo obriga à integraçáo e incorporação de perfis profissionais polivalentes e interdisciplinares.

\section{Conclusão}

O Tratado de Bolonha pretende concretizar uma reforma no ES com vista a uma Europa de Conhecimento de Qualidade competitiva e transparente.

As suas implicaçóes reflectem-se no papel da universidade e de todos os elementos envolvidos no processo de aprendizagem. É de salientar a necessidade de colaboração entre os estudantes, docentes, serviços e a própria universidade num alinhamento colectivo.

O novo paradigma pedagógico assenta no conceito de Aprendizagem e eleva o papel do aluno no processo. Este orienta o próprio estudo a partir das novas tecnologias de informação disponibilizadas na biblioteca.

Recorrendo a uma aprendizagem significativa, é imperativa uma formação de Literacia de Informação para o seu sucesso. Pretende-se criar pesquisadores autónomos com habilidades nas novas tecnologias e recursos de informação.

A importância das TIC's torna-se incontestável e a disponibilização dos respectivos recursos é imprescindível.

O processo de criaçáo de conhecimento baseia-se no conceito de ciência colaborativa desde o decurso da pesquisa à disseminação e divulgação.

No âmbito da produção de conhecimento científico, é de realçar a importância e a necessidade da criaçáo de repositórios digitais numa perspectiva de livre acesso de informação. Este projecto tem sido abraçado por várias bibliotecas de ES no sentido de criação de valor institucional e participação no processo. 
A biblioteca torna-se um centro de recursos cuja responsabilidade é disponibilização e actualizaçáo da infra-estrutura tecnológica requerida pelos novos conteúdos curriculares.

Simultaneamente, surge como um centro de estudo, onde se realizam os trabalhos de grupo que pretendem a aprendizagem colectiva.

A biblioteca do ES depara-se com uma nova missão e necessita de se ajustar, com recursos tecnológicos, infra-estruturas e recursos humanos adequados às novas exigências dos seus utilizadores.

O perfil do profissional de informação assume, de forma inevitável, competências multidisciplinares e especializadas ao nível das tecnologias de informação e da Literacia de Informação.

O perfil e competências profissionais de Ciência da Informação, aliadas ao sentido de oportunidade de mudança nas bibliotecas do ES podem representar não apenas uma mais-valia para instituição (como tem sido até hoje) mas sim como um elemento activo, de colaboração, articulaçáo e catalisador do processo de aprendizagem e de criação e disseminação do conhecimento.

A biblioteca de ES assume um papel activo no processo de aprendizagem e tem como responsabilidade reforçar laços entre a comunidade e estabelecer redes de colaboração entre as Direcçóes Académicas e a Comunidade.

CI pretende elevar a biblioteca do ES à categoria de chave estratégica numa Organização Inteligente, de Qualidade e Competitiva.

\section{Referências bibliográficas}

Azevedo, A. M. G. G., Fiolhais, C. M. B., Costa, J. F. F. d., Jahnke, H.-R., França, I., Veloso, L., et al. (2006). Reorganização e Reestruturação das Bibliotecas da Universidade de Coimbra [Versão Electrónica], 83. Obtido a 19 de Julho de 2009, em http://www.uc.pt/sibuc/Pdfs/ relatorio.

Boy, J. Z., Roldán, M. L. G. O., García, C. H., Villar, A. C., Zapatero, D. C., Simón, L. F. R., et al. (2006). Investigación, docencia y biblioteca en el marco del Espacio Europeo de Educación Superior Docente [Versão Electrónica], 19. Obtido a 19 de Julho de 2009, em http://eprints. ucm.es/7619/1/PIE06.pdf.

Do, Q. (2008). Talking to a Spanish academic librarian about the Bologna Declaration [Versão Electrónica]. Elsevier Library Connect Newsletter, 6, 16. Obtido a 9 de Março de 2009, em http://libraryconnect.elsevier.com/lcn/0601/lcn0601.pdf.

Geleijnse, H. (2005). Integrating the digital library with teaching, learning and research. Artigo Científico apresentado na conferência Rebiun Conference of Spanish University Libraries. Obtido a 26 de Julho de 2009, em www.rebiun.org/export/docReb/hans_1.ppt.

Gómez, R., López, M. \& Rovira, A. (2003). A New Type of Library for the New European Space for Education: UPC's Learning and Research Resources Centre. Artigo Científico apresentado na conferência IATUL Conference Proceedings 2003. Obtido a 12 de Julho de 2009, em http://www.iatul.org/doclibrary/public/Conf_Proceedings/2003/GOMEZ_fulltext.pdf.

Mas, M. T. (2006). La biblioteca como centro de recursos: nuevos modelos para realidades cambiantes. Artigo Científico apresentado na conferência Jornada profesional Bibliotecas y educación: una relación a debate. Obtido a 19 de Julho de 2009, em http://www.bne. 
es/es/Servicios/NormasEstandares/DocumentosProfesionales/BibliotecasyEducacion/ Docs/060619_biblioteca_como_centro_de_recursos.pdf.

Moscoso, P. (2003). La nueva misión de las bibliotecas universitarias ante el Espacio Europeo de Enseñanza Superior. Artigo Científico apresentado na conferência I Jornadas CRAI - Los Centros para Recursos del Aprendizaje y la Investigación: nuevos espacios arquitectónicos para el apoyo a la innovación docente. Obtido a 18 de Julho de 2009, em http://dspace. uah.es/jspui/bitstream/10017/809/1/PonenciaREBIUNMallorca.pdf.

Pacheco, E. L. M. (2009). A literacia da informação e o contributo da biblioteca universitária [Versão Electrónica], 8. Obtido a 15 de Julho de 2009, em http://badinfo.apbad.pt/ Congresso9/COM62.pdf.

Peterson, J. H. (2006). The Library as Competive Advantage. Artigo Científico apresentado na conferência EBSLG-conference Obtido a 20 de Junho de 2009, em http://www2.bi.no/ library/ebslg/EBSLG\%20presentation\%20Heide\%20Petersen.pdf.

Peyrolon, M. C. F. G. (2005). Las Bibliotecas Universitarias en el Espacio Europeo de Educación Superior: un cambio estratégico. Artigo Científico apresentado na conferência 9a Jornadas Espanolas de Documentación FESABID. Obtido a 3 de Julho de 2009, em www.fesabid. org/madrid2005/descargas/.../fernandez_mc.pps.

Rocha, M. M. V. \& Araújo, E. A. d. (2007). Competência Informacional e Atuação do Profissional da Informação - Bibliotecário. Artigo Científico apresentado na conferência VIII ENANCIB - Encontro Nacional de Pesquisa em Ciência da Informação. Obtido a 20 de Julho de 2009, em www.infolitglobal.info/getdoc.php?did=11.

Rodrigues, M. E. F. \& Dumont, L. M. M. (2004). A Lógica da Organizaçâo e Distribuição do Conhecimento na Universidade: implicaçōes no processo de ensino-aprendizagem, em especial, nas áreas de Biblioteconomia e Ciência da Informação [Versão Electrónica]. DataGramaZero - Revista de Ciência da Informação, 5, 14. Obtido a 13 de Julho de 2009, em http://dgz. org.br/abr04/Art_03.htm.

Silva, A. M. d. (2008). Inclusão Digital e Literacia Informacional em Ciência da Informação [Versão Electrónica]. Prisma.com, 16-41. Obtido a 23 de Julho de 2009, em http://prisma. cetac.up.pt/16_Inclusao_Digital_e_Literacia_Informacional_em_Ciencia_da_Informacao_ Armando_Malheiro_Silva.pdf.

Silva, A. M. d., Marcial, V. F. \& Martins, F. (2009). A Literacia informacional no Espaço Europeu de Ensino Superior [Versão Electrónica], 13. Obtido a 20 de Julho de 2009, em http://badinfo. apbad.pt/Congresso9/COM31.pdf.

Silva, A. M. d. \& Ribeiro, F. (2008). Formação, perfil e competências do profissional da Informação. Artigo Científico apresentado na conferência Congresso Nacional de Bibliotecários, Arquivistas e Documentalistas, $8 .^{\circ}$. Obtido a 17 de Julho de 2009, em http://badinfo. apbad.pt/congresso8/com16.pdf.

Trujillo, D. M. (2004). El nuevo concepto de biblioteca universitaria. Artigo Científico apresentado na conferência Los recursos electrónicos en la colección de la Biblioteca Obtido a 20 de Julho de 2009, em http://www.ucm.es/BUCM/jornadas/bcauniv/nuevo_concepto_bu.pdf.

UNICA. (2006). Trends in Education and Research: Developing Skills and Communication across Europe. Artigo Científico apresentado na conferência UNICA Library Seminar 2006. Obtido a 11 de Julho de 2009, em http://www.ulb.ac.be/unica/docs/librarians_2006_conclusions. pdf. 